\title{
Nuclear waste plans enter critical phase
}

London. Britain's newly privatized nuclear power industry is facing a critical few months as it contemplates how to dispose of up to 300,000 cubic metres of radioactive waste by early next century - and answer critics who claim that its plans are unsafe.

At stake is the outcome of a 66-day planning inquiry into an experimental underground rock laboratory below Sellafield, Cumbria, in northwest England. The industry's waste disposal company, Nirex, claims it needs the laboratory to assess the suitability of the rocks for a deep repository for lowand intermediate-level radioactive waste.

But Nirex needs to convince Cumbria County Council of the desirability of its plans. The council is opposed to the plans, and has already rejected one planning application for the rock laboratory. The council, with some scientists and environmental groups, says more basic research is needed. It is also concerned that the laboratory may be converted into part of the repository.

The final decision, based on an inspector's report of the inquiry, which ended on 1 February, is now awaited from John Gummer, secretary of state for the environment. If the decision goes against Nirex, its plans would be set back at least five years, which could prove costly. Perhaps more damagingly, Nirex could be faced with the prospect of being turned away by every local planning authority in the country.

To make matters worse, Nirex has been criticized by the Royal Society for holding back important data that need to be assessed by government regulators, and for not subjecting its science to independent peer review.

Critics of Nirex's approach also include the UK government's Radioactive Waste Management Advisory Committee
(RWMAC), which is compiling a report on Nirex and peer review, as well as the environmental groups Friends of the Earth (FoE) and Greenpeace.

The situation has resulted in a tense debate within Nirex. The company's scientists are unlikely to give their approval to a Sellafield repository unless they are convinced that the site is safe. But major shareholders are said to be becoming restless. The longer the issue is left unresolved, the greater the likelihood that they could lose potential overseas contracts.

Nirex has already spent $£ 400$ million (US\$636 million) on research aimed at assessing the safety of underground disposal, particularly after the repository's expected 50-year period of use. It has drilled 27 boreholes to investigate the geology and hydrogeology. A further $£ 200$ million will be spent on the rock laboratory.

Nirex's problems began in 1991, when it announced Sellafield as its proposed repository site from a short-list of 12 locations. According to the company, Sellafield was chosen using a technique known as multiattribute decision analysis, in which each site is assessed by adding up scores assigned to technical, social and economic considerations. But a detailed explanation of this decision was not released immediately.

This was pointed out by the Royal Society in its report on radioactive waste disposal published in November 1994, which also acknowledged that the site was convenient, as most of the waste would come from the nearby Sellafield reprocessing plant of British Nuclear Fuels (BNFL). The Royal Society nevertheless says it retains an "open mind" as to the suitability of Sellafield.

Andrew Stirling, a research fellow at the Science Policy Research Unit at the Univer-

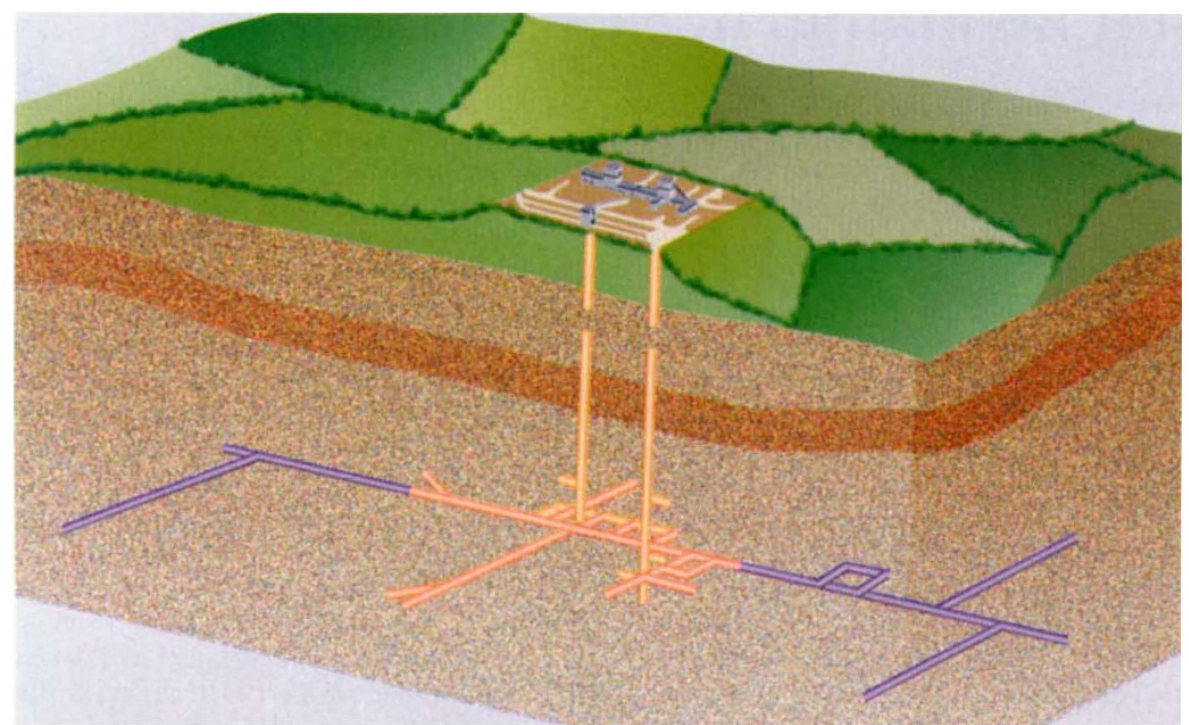

Going underground: Nirex claims a rock laboratory (above) is needed to assess site safety. Critics contend that shaft-sinking could disturb the hydrogeology Nirex seeks to examine. sity of Sussex, assessed Nirex's more complete account of its decision-making on behalf of Greenpeace. He says that he found inconsistencies in the methodology. For example, "long-term public safety was assigned a very low weighting". Nirex justified this on the grounds that the site would not have been shortlisted if its safety to the public had been in question.

Nirex's research plans, however, have been welcomed by many in the scientific community, including RWMAC and the Royal Society, with the extra caveats that the company must provide enough time to gather and assess data, and subject its science to independent peer review. Nirex has announced that it plans to deposit waste in the repository by 2012. But John Holmes, the agency's director of science, says this date is not set in stone and depends on the results of the scientific investigation.

But others are unsure about Nirex's research plans. David Smythe, professor of geophysics at the University of Glasgow, was a member of a BNFL review panel assessing possible repository sites. Smythe says he was initially in favour of Sellafield, but changed his mind when the site's geology was found to be more complex than previously thought. He resigned in 1991, sensing that the nuclear industry was using the panel to "rubber stamp" the choice of Sellafield. "It was science in the service of politics."

Smythe is one of a number of observers who believe that Nirex's scientists are still caught up in the old 'secrecy culture' that Britain's nuclear industry is slowly beginning to shake off. One scientist who has worked extensively in radioactive waste disposal, but who declines to be identified, says Nirex scientists have continually to struggle to convince the company's management of the need to make research results public.

Rachel Western, a nuclear researcher for FoE, points out that Nirex's 'safety studies', normally published about 20 times a year, were reduced to a trickle during the rock laboratory inquiry.

Holmes says the reduced frequency of the studies is temporary as Nirex had to devote all available resources to the inquiry. $\mathrm{He}$ adds that the company publishes far more than comparable commercial organizations, such as British Coal. "But because we carry the nuclear label, there is this presumption that we are hiding something." Nirex, he says, plans to publish more often and to have some work reviewed by an outside panel of scientists.

But there remains no completely independent mechanism to assess the company's research. Nirex will need to apply to the government's Environment Agency for authorization to build the repository. But under recent government regulations - known as 'the polluter pays' - Nirex pays to have $>$ 
- its own research assessed.

This arrangement has already run into trouble. Almost two years after announcing its decision to construct a rock laboratory, Nirex pulled out of an arrangement with the government's pollution inspectors to fund an assessment of its waste disposal plans, midway through the study.

In a report, the inspectors noted that Nirex had delayed providing key information. The Royal Society, too, noted communication difficulties between the inspectors and Nirex. Holmes, however, says that particular assessment was geared to-wards lodging a repository planning application in 1992, and ended "by mutual arrangement". Both organizations, he adds, are consulting over a fresh research assessment.

Miro Ivanovich, professor of geochemistry at the University of Reading, who has been involved in Nirex work, says future assessments must be made more transparent. He says Nirex should be asked to place its research funds under independent control. "I'm not criticizing the quality of what they [Nirex] do," he says. "But people must be convinced that there is no conspiracy."

Part of the problem stems from the shortage of independent hydrogeological expertise in the UK radioactive waste management community. Western says that both FoE and Cumbria County Council had difficulty in finding independent experts to review Nirex's evidence to the rock laboratory inquiry. "The majority of hydrogeologists working in radioactive waste management have had some contact with Nirex," says Jane Dotteridge, lecturer in hydrogeology at University College London and chair of the hydrogeology group of the Geological Society of London.

Dotteridge says that graduates from several new MSc courses in radioactive waste management could herald a change. But this is unlikely while Nirex remains the

\section{Rock laboratory faces key questions}

London. Before the seal is set on Sellafield in Cumbria, northwest England, as the home of Britain's first underground nuclear waste repository, Nirex will need to convince itself - and its critics that the waste poses no danger to present and future generations.

The greatest potential threat is from radionuclides finding their way back to the surface long after the cement-filled steel drums containing the waste have been corroded by groundwater seeping into the repository. Nirex needs to assess how quickly water will enter the repository and corrode the containers.

One of the most difficult tasks is to predict the fracture pattern of the rocks, and then to calculate the speed and direction of the groundwater flow. Nirex's safety assessment also needs to consider the effects of gas deposits, earthquakes and climate change - an ice age is predicted to return to Cumbria within 100,000 years.

The organization has begun to address some of these issues by drilling deep boreholes near the planned repository. It now wants to build its controversial rock laboratory, consisting of two 5-metre-diameter shafts dug 790 and 920 metres into the ground, connected to a network of tunnels.

But critics believe there is more borehole work to be done. Opposition to the

dominant funder of research.

Holmes discounts the need for any additional external reviews of Nirex's work, however, and says there "is no shortage of alternative opinions". The public inquiry for the repository will, he says, provide a good scheme centres on concerns that Nirex has not fully considered the impact on the site's hydrogeological and hydrogeochemical conditions of constructing the laboratory.

The Radioactive Waste Management Advisory Committee (RWMAC) and Friends of the Earth have pointed out that Nirex must provide evidence that building the laboratory will not disturb the natural environment that it aims to monitor. John Holmes, Nirex's director of science, says the company has commissioned four scientists to assess this issue. He says their recommendations will be published and acted upon.

In addition, the Royal Society and RWMAC have suggested that Nirex's relatively short research timetable may not yield enough data for a proper safety assessment and should be extended. Nirex plans to apply for planning permission for the repository by 1998-99. But these organizations point out that accurate data will not be obtained until environmental conditions settle down, which could take up to three years after the laboratory's construction.

Holmes says that Nirex is committed to keeping the rock laboratory open for nearly 10 years, and will walk away from the site if the results show that a Sellafield repository, as currently proposed, is potentially unsafe. E. M.

test of Nirex's arguments. He says the grilling that Nirex received at the inquiry for the rock laboratory from environmentalist groups should be ample evidence that "there is no chance that we can pull the wool over people's eyes".

Ehsan Masood

\section{US panel approves salt bed burial in New Mexico}

Washington. The United States can safely bury intermediate nuclear waste in a salt bed under southern New Mexico, provided that future generations do not try to drill for oil through the dump, according to a panel of experts convened by the National Research Council (NRC), the operating arm of the National Academy of Sciences.

Their recommendation will increase the chances that the proposed Waste Isolation Pilot Plant (WIPP) will be constructed. The Department of Energy, which wants to build the dump in order to dispose of plutonium cuttings and other debris from the nuclear weapons programme, will formally apply this week to the Environmental Protection Agency (EPA) for permission to do so.

The panel, chaired by Charles Fairhurst, a mining professor at the University of Minnesota, found that, in the absence of human disturbance, the proposed repository would successfully isolate the barrels of solid waste for at least ten thousand years. In the event of drilling or other human activity, the panel said, engineering methods are available that would minimize the chances of radioactive releases.

Plans to build the WIPP near Carlsbad, New Mexico, have been under consideration for almost twenty years, and experimental storage areas have been dug out of the salt 2,000 feet underground. The salt bed is an attractive medium for dumping because the salt is virtually impermeable to water, but will gradually close up around the waste and seal it, like a viscous fluid.

WIPP would store up to 137,000 cubic metres of the solid waste, held in 55-gallon steel drums. The total radiation inventory in the repository would be a thousand times less than at the proposed store for spent nuclear fuel at Yucca Mountain, Nevada.
Unlike Yucca Mountain, WIPP has the support of many politicians in its home state.

"In the undisturbed condition, we see no credible scenario for the release of radionuclides" from the proposed dump, says Fairhurst, pointing that the situation is different in other countries which have abandoned the idea of repositories.

The panel noted that EPA regulations assume that oil and gas drilling activity will take place over the next 10,000 years at the rate now prevalent in the surrounding area. This assumption is "highly conjectural and lacks scientific foundation," Fairhurst says.

The panel suggests that the EPA should reconsider its assumptions about drilling activity, and that the Department of Energy should continue work on techniques to increase WIPP's resilience to human disturbance, the nature of which, it concedes, is impossible to predict.

Colin Macilwain 